\title{
Transgeneridade e Santo Daime: as (im)possibilidades de uma busca espiritual ayahuasqueira
}

\author{
Alana Pereira da Silva ${ }^{1}$ \\ Universidade Federal do Sul e Sudeste do Pará
}

Resumo: No artigo, reflito sobre questões éticas e metodológicas no campo dos psicoativos e busco compreender as (im)possibilidades de participantes, "fardantes" (iniciantes) e "fardados" (iniciados) transgêneros e transexuais nos "trabalhos" do Santo Daime na cidade de Marabá (PA), sudeste paraense, na Amazônia Oriental. A pesquisa foi realizada através do método da observação participante, não como mera retórica, mas como expressão de uma posição ética na ciência que possibilite uma imersão etnográfica e considere o insight antropológico.

Palavras-chave: Transgênero; Santo Daime; Amazônia; Espiritualidade. 


\title{
Transgenerity and Santo Daime: The (im)possibilities of a spirituality search ayahuaqueira
}

\begin{abstract}
In the article, I ponder about the ethics and methodologies about psychoactives and look to understand the (im) possibilities of the transexuals or transgenders participants, "fardantes" (beginners) and "fardados" (initiates) at the Santo Daime's works the city of Marabá (PA), at southeastern Pará, in eastern Amazon. The research was made through the observation/participation method, not as mere rhetoric, but as an expression of an ethical position in science that allows an ethnographic immersion and considers anthropological insight.
\end{abstract}

Keywords: transgender; Santo Daime; Amazon; spirituality.

\section{Transgeneridad y Santo Daime: Las (im)possibilidades de una búsqueda de espiritualidad ayahuasqueira}

\begin{abstract}
Resumen: En el artículo, reflexiono sobre cuestiones éticas y metodológicas en el campo de los psicoactivos y trato de comprender las (im) posibilidades de los participantes, "uniformes" (principiantes) y "uniformes" (iniciados) transgénero y transexual en las "obras" de Santo Daime en la ciudad de Marabá (PA), sureste de Pará, en la Amazonía Oriental. La investigación se realizó a través del método de observación participante, no como mera retórica, sino como expresión de una posición ética en la ciencia que permite una inmersión etnográfica y considera insignes antropológicos.
\end{abstract}

Palabras clave: transgénero; Santo Daime; Amazonas; espiritualidad. 
Respeitar os seus irmãos

com alegria e com amor

Para todos conhecer e saber dar o Seu valor

(Todos querem ser irmãos, Raimundo Irineu, Hino 118, Cruzeiro Universal)

\section{O Santo Daime no sudeste paraense}

A minha pesquisa de campo iniciou em 2016, realizada de acordo com a proposta da disciplina Teorias Antropológicas, cursadas durante a graduação. Nesse exercício descritivo e de estranhamento antropológico conheci uma nova religião que tem seu sacramento baseado em uma substância psicoativa. A história do Santo Daime, fundada no Acre pelo maranhense Raimundo Irineu Serra é de uma complexidade histórica, social, cultural, política e econômica, visto que se trata apenas de uma doutrina ou um conjunto de princípios cristãos, mas possui elementos da cultura indígena, africana e oriental. Não se tem uma época exata de quando esta bebida foi descoberta, entretanto a bibliografia ayahuasqueira demonstra que ela recebe vários nomes: "daime", "oasca", "yajé”, "vegetal", "caapi”, mais conhecida como ayahuasca, isto é, o "cipó das almas".

Assim como seus vários nomes, diversos são os contextos religiosos que tem como sacramento esta bebida psicoativa (União do Vegetal, Barquinha, Umbandaime e outros centros ayahuasqueiros). Seus usos perpassam por estigmas sociais que relacionam a bebida a efeitos alucinógenos, contudo, compreendo que se trata de uma substância enteógena, "aquilo que leva o divino dentro de si", ou seja, "Deus dentro" (MACRAE, 1992: 17-25).

Para as pessoas que lerem este artigo ${ }^{2}$ é importante explicitar algumas categorias "nativas" da religião mencionada para dinamizar a leitura. No Santo Daime, os rituais (realizados quinzenalmente) são chamados de "trabalhos", nos quais as "fardadas" (iniciadas) utilizam roupas de acordo com as suas "expressões de gênero"3. Em dias comuns os homens usam calça azul e camisa branca social e as mulheres, saia longa azul e blusa branca social. Nos dias de festejos, ambas as fardas são brancas, acrescentando-se um paletó branco para os homens e para as mulheres uma coroa, um saiote com faixa verde, um broche chamado de "roseta" e fitas coloridas no ombro esquerdo que são chamadas de "alegrias".

E para melhor compreensão da minha imersão e da abordagem do gênero na religião Santo Daime, é necessário que eu apresente brevemente alguns passos da trilha etnográfica neste campo, bem como, as ferramentas, métodos e questões éticas da pesquisa. Visitei três igrejas daimistas e dois centros ayahuasqueiros na cidade de Marabá (PA). Foram quase seis anos de imersão e, nesse período, participei de mais de setenta "trabalhos". O método utilizado na pesquisa foi a observação participante, na qual problematizo as experiências da localização social em que estou inserida e reflito sobre a afetação da pesquisadora em campo. As técnicas e ferramentas de trabalho são as entrevistas estruturadas e semiestruturadas, com uso de gravador e mantenho um diário de campo que é necessário para a prática e registros de insights dos trabalhos de campo antropológicos.

\footnotetext{
${ }^{2}$ Resolvi, como postura ético-metodológica, não chamar leitor ou leitora as pessoas que lerem este artigo, visto que, as letras que encerram as palavras mencionadas são entendidas como relacionados a pronomes generizados ou generificados (por gênero feminino ou masculino).

3 Como você se expressa ou como você é lido pelas pessoas em sua volta.
} 
Neste artigo apresento os resultados de pesquisa do meu TCC4. Muitas questões são pertinentes para abordar em um trabalho como este, dentre as referentes ao gênero, problematizo as experiências de transgêneros no Santo Daime. Neste texto descrevo o campo e o "trabalho" de "feitio" que é um momento ritual de preparação da bebida sagrada 5 , na qual observo a participação de pessoas trans e questiono as (im)possibilidades desses atores sociais enquanto "visitantes", "fardantes" ou "fardados" da doutrina.

\section{A "retórica" da observação participante: sobre "ser afetado"}

Para refletir sobre as metodologias e questões éticas que atravessam as pesquisas no campo ayahuasqueiro, em especial porque a pesquisadora é obrigada a ingerir o chá, também é necessário problematizar a fronteira que separa a pesquisadora e os "nativos". No contexto abordado aqui, a pesquisadora não é uma mera observadora externa, mas é também, considerada parte do grupo. Aqui sou um exemplo de pesquisadora que está a "tornar-se nativa"6 (MAAS, 2015).

É importante frizar que as minhas inquietações a respeito de ser ou não afetada em campo foram superadas, isto porque, observação participante ou participação observante (INGOLD, 2019) é mais que uma retórica, esta é a expressão de uma posição ético-científica que possibilita uma imersão etnográfica e a absorção dos fenômenos sociais, baseada no respeito ao grupo investigado (WHYTE, 2005). Logo, "ser afetado" na minha experiência, não se assemelha às experiências de Favret-Saada (2005), pois a autora conseguiu obter informações em campo a partir da aceitação de "ser afetada" pela feitiçaria do grupo e investe anos de questionamentos sobre dois obstáculos enfrentados: 1) se ela "participasse" de um ritual de "desenfeitiçamento" o trabalho se tornaria uma aventura pessoal; 2) se ela tentasse "observar" ia se manter à distância e não teria nada para observar.

Os conflitos e turbulências enfrentados por Favret-Saada (2005) foram compartilhados por mim, em parte, desde quando recebi a "instrução do fardamento". Passei cerca de sete meses pensando se o que eu havia vivido no momento da "força" (efeito corporais e experiências extracorporais do chá) era realidade e como essa decisão afetaria minha pesquisa.

Recordei sobre alguns debates a respeito da autoetnografia e refleti sobre os riscos da minha pesquisa ser interpretada como um texto biográfico. Me observei em aproximadamente 18 rituais com a bebida que, no meu caso, não se tratava de analisar como eu conseguia realizar uma pesquisa e saber lidar com seus efeitos psicoativos, pelo contrário, cheguei à constatação de que pensar sobre isso durante os rituais atrapalhava o meu processo pessoal de autoconhecimento (proposta ritualística), obstruía o que os adeptos da doutrina chamam de "corrente energética do salão" e também bloqueava os insights antropológicos que sempre vêm à mente antes, durante e depois dos rituais7.

Questionei também se a decisão de me tornar "nativa" era para ter acesso à outras festividades e rituais específicos de pessoas "fardadas" no centro que

\footnotetext{
4 Trabalho de Conclusão de Curso.

5 Junção da folha da chakrona (Psychotria viridis) e do cipó jagube (Banisteriopsis Caapi).

${ }^{6}$ Após quase 5 anos de experiências etnográficas e espirituais no Santo Daime, decido me fardar (aderir a doutrina da

Rainha da Floresta).

7 Favret-Saada (2005) viveu a mesma angústia, mas escreveu muitas notas para depois analisar o seu engajamento na pesquisa.
} 
participo, tais como: os aniversários, as reuniões e a Santa Missa ${ }^{8}$. Para evitar que a minha pesquisa seja confundida como biografia e, atrelada às percepções de demandas que surgiam em campo a respeito do gênero (mas especificamente a transgeneridade) procurei inter-relacionar as questões ético-metodológico das pesquisas com psicoativos e das abordagens em diversidades de gênero, visto que, nas igrejas marabaenses, muitas e muitos jovens transgêneros têm frequentado as igrejas do Santo Daime e/ou estão em processos de "fardamento".

\section{"A energia não tem gênero": sobre essências e tabus}

Transgênero são todas as pessoas que não se reconhecem enquanto pertencentes ao gênero que lhe impuseram ao nascer. A transexualidade, travestilidade e não binaridade são identidades que não correspondem ao ideal cisgênero. Essas pessoas, na maior parte dos casos, sentem desconforto com seus corpos, por isso adotam características do gênero a qual se identificam. Esse desconforto é denominado pelos interlocutores da pesquisa como "disforia".

De acordo com Amara Moira (2017) é importante compreender, inicialmente, que ser trans não é sinônimo de uma pessoa com transtorno, uma doença ou com um problema psiquiátrico. Segundo a autora, ser trans significa uma pessoa que não se identifica com o gênero que lhe designaram ao nascer, isto porque a sociedade associa as genitálias à determinadas categorias do gênero. Portanto, é ofensivo e caracteriza-se transfobia dizer "o travesti”, pois essa é uma identidade feminina. A identidade de gênero é sobre como as pessoas se entendem, sobre como querem viver suas vidas e como imaginam seus corpos. A luta de pessoas trans é para que cada ser tenha o direito de descobrir quem é. A cisgeneridade, por outro lado, são as pessoas que se identificam com a genitália e o gênero designado ao nascer.

O gênero como uma categoria de análise (e não um recorte de pesquisa) têm se mostrado cada vez mais amplo e urgente. É importante contextualizar que a sigla LGBT passou por inúmeras modificações. Na década de 1990, a sigla ainda recebia as iniciais GLS (Gay, Lésbicas e Simpatizantes) para definir um movimento de pessoas não heteros e pessoas que, até então se entendiam enquanto héteros e apoiavam o movimento.

Com o passar dos anos as reinvindicações políticas pela modificação da sigla deixa o debate cada vez mais interessante e amplo. O "L" assume o protagonismo na luta, de modo a dar visibilidade ao movimento de mulheres lésbicas e inclui o "B" referente às pessoas bissexuais que sentem atração pelo gênero feminino e masculino. A letra "T" é inserida na sigla, embora não se trate de sexualidade, mas de identidade de gênero.

IDENTIDADE DE GÊNERO

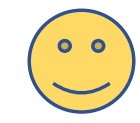

SEXUALIDADE

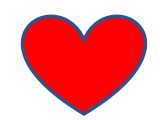

Na contemporaneidade, outras "letras" são inseridas de modo a representar toda a diversidade sexual e de gênero existente. Nesse sentido, a identidade

${ }^{8}$ São realizadas às primeiras segundas-feiras de cada mês, com foco nas pessoas "desencarnadas" que estão "presas neste plano por algum motivo", conforme a afirmação de um das (os) dirigentes. 
sexual de uma pessoa não define seu gênero, por exemplo, uma mulher trans pode ter um relacionamento afetivo com uma mulher cis e este ser um casal lésbico. Assim como um homem trans ao se relacionar afetivamente com uma mulher (cis ou trans) estão em relacionamento hétero, mas que não necessariamente sejam héteros. Estas pessoas podem ser pansexuais, bissexuais ou héteros.

É primordial explicar que sou uma mulher cisgênera e bissexual, não para demarcar um limite de não afetação em campo, mas para que entendam o meu "lugar de fala" em uma pesquisa desafiadora e transgressora. Djamila Ribeiro (2017) expõe a ideia de que "todo mundo tem um lugar de fala", pois as pessoas falam de sua localização social. Além disso, pensar lugar de fala é uma postura ética que possibilita percepções das hierarquias, das desigualdades, da pobreza, do racismo e do sexismo ${ }^{9}$. A filósofa menciona os possíveis equívocos entre lugar de fala e representatividade, contudo, ativistas transgêneros criticam a conduta de pessoas cisgêneras que se comportam como se pessoas trans não falassem ou escrevessem sobre elas mesmas e desenvolvem suas pesquisas sem considerar os seus pontos de vista, seus protagonismos e suas visões de mundo.

Quando cito o "lugar de fala", não pretendo deixar de lado a importância da representação, afirmo ser importante espaços auto-organizados para que pessoas que componham o mesmo grupo identitário possam se perceber, sem se submeter aos filtros e rótulos de terceiros. Portanto, da localização social em que estou inserida, me coloco a questionar se eu, enquanto cis, estou verdadeiramente escutando as pessoas trans envolvidas na pesquisa e àquelas e aqueles que já tem voz e não só falam sobre as opressões vividas cotidianamente, mas gritam e imploram por respeito.

Sob olhos imparciais, muitos cientistas acreditam que a distância possa garantir a objetividade da pesquisa. As ciências humanas e sociais estabeleceram, por muito tempo, a imparcialidade e neutralidade como premissa fundamental para o desenvolvimento da pesquisa científica das culturas e sociedades. Gilberto Velho (2004) demonstra que na pesquisa antropológica não se deve evitar envolvimento com os interlocutores, haja vista que, para conhecer certas áreas ou dimensões de uma sociedade é necessária uma vivência durante um período de tempo, pois existem aspectos culturais que não são explicitados e que, a exemplo da minha experiência, exige um esforço maior em não ser transfóbica e, bem menos pregar juízo de valor na interpretação da estrutura da "doutrina da floresta".

Estas inquietações perpassam todo o trabalho e certamente confirma que o distanciamento e não envolvimento com o grupo pesquisado não torna a pesquisa etnográfica mais objetiva, e sim, mais generalizada. Clifford (2016), por exemplo, diz que a cultura é vista como composta por representações e códigos seriamente contestados e que sua escrita e descrição perpassam por questões éticas. A autoridade etnográfica que possuo enquanto pesquisadora na área das ciências sociais permite que eu consiga me localizar enquanto "nativa" que estuda a própria cultura e insere, na investigação antropológica, a categoria de análise de gênero para problematizar o campo.

Agora que situei, no texto, minha localização social a respeito do lugar de fala, prossigo para as apresentar, as contínuas formas de resistência que as pessoas trans passam no processo de exercício da sua espiritualidade dentro (ou fora) de religiões, seja no catolicismo, protestantismo, nas religiões afro-brasileira, como o caso de Quesia Sonza, que relatou através de postagem de vídeo na sua rede social, em 2020, sobre a transfobia vivida por ela em um terreiro candomblecista,

9 Cita Roseane Borges em uma matéria (RIBEIRO, 2017: 46) - DIAS, TATIANA; MOREIRA, MATHEUS. "O que é lugar de fala e como ele é aplicado no debate público”. Nexo Jornal, 16 jan.2017. Disponível em: <https://goo.gl/KgMHZQ> 
sendo expulsa do local por ser uma mulher trans ${ }^{10}$, mas que felizmente encontra um outro terreiro em que é acolhida e respeitada.

Tarso Alexandre Brant, diz que a espiritualidade em sua vida o ajudou a aprender e refletir sobre quem ele é, quais são os seus valores e o que importa para a vida dele, em razão de passar a frequentar sessões de um centro espírita kardecista (MOIRA, 2017). Concordo com Benedito (2020) de que não tratar desses assuntos nas religiões e centros espíritas apenas irá causar mais sofrimento às pessoas que precisam de espaços de acolhimento, de escuta e de respeito.

Pesquisadoras ayahuasqueiras e "daimistas" (categoria de autoatribuição dada pelos iniciados no Santo Daime) vêm trabalhando temas e abordagens sobre gênero e sexualidade, levantando a urgência de se questionar concepções de gênero, a moralidade daimista e a aproximação de alguns líderes e adeptos à agenda bolsonarista. Nesse sentido, as opressões sofridas por Raimundo Irineu são levadas em consideração para a afirmação de que "ayahuasca é revolucionária" (BENEDITO, 2020). E não há dúvidas de que o contexto em que o Santo Daime foi constituído era de, sobretudo, racismo intensificado em um Brasil pós abolucionista.

Quando reflito sobre as (im)possibilidades de pessoas trans exercitarem a espiritualidade daimista, me refiro aos relatos de situações em que essas pessoas são constrangidas e/ou forçadas a integrar um "batalhão" que não condiz com sua identidade de gênero. Deste modo, me ponho a questionar tais (im)possibilidades desse público como praticantes ("fardantes"/"fardados") ou simpatizantes desta doutrina.

Nas igrejas marabaenses, estas "possibilidades" estão pautadas na "passabilidade de gênero" que está relacionado à leitura social que as pessoas fazem dos corpos trans. Corpos trans existem e devem ser respeitados nas suas pluralidades, entretanto, muitas iniciam procedimentos hormonais e utilizam instrumentos que estão para além de parecerem mulheres ou homens "de verdade". A "passabilidade" é por si um tanto problemática, pois reforça a obrigatoriedade de expressões de gênero binárias.

De acordo com a ANTRA ${ }^{11}$ existe a possibilidade de acesso ao Sistema Único de Saúde (SUS) para o "processo transexualizador", introduzido em 2008, de acordo com, a Política Nacional de Saúde Integral LGBT+ do Ministério da saúde e na Portaria $2803 / 2013^{12}$. A portaria em questão foi redefinida e ampliada passando a incorporar como usuários os homens trans e as travestis, "tendo em vista que, até então apenas as mulheres trans eram assistidas pelo serviço" (BENEVIDES, s/d: 1):

O cuidado com a população trans é estruturado por dois componentes: a Atenção Básica e a Atenção Especializada. A Básica refere-se à rede responsável pelo primeiro contato com o sistema de saúde, pelas avaliações médicas e encaminhamentos para tratamentos e áreas médicas mais específicas e individualizadas.

A Especializada é dividida em duas modalidades: a ambulatorial (acompanhamento psicoterápico e hormonização) e a hospitalar (realização de cirurgias de modificação corporal e acompanhamento pré e pós-operatório).

Por muito tempo a transexualidade foi tida como um distúrbio, uma patologia a ser tratada, obrigatoriamente, com cirurgia de redesignação sexual e hormonioterapia. É necessário problematizar a ideia de processo transexualizador, pois a "disforia de gênero" não necessariamente é "tratada" com cirurgias. Alguns homens trans, mulheres trans e não binárias (os) relatam em suas redes sociais

$10 @$ quesiasonza (instagram) "Fui expulsa do Candoblé por ser Trans”, 2020. 
que são "boycetas", mulheres "de pau” e que não precisam se encaixar nas normas cisgêneras para serem quem são.

Importante frisar, que o processo transexualizador não se trata de uma "afirmação de gênero", segundo o texto publicado no antrabrasil.org, nenhuma modificação corporal (ou a ausência dela), apesar de serem importantes para a comunidade, definem as identidades transgêneras. Por isso, utilizam o termo "cirurgias de modificações corporais" em referência aos procedimentos cirúrgicos. O mesmo posicionamento vale para a hormonioterapia ou transição hormonal, visto que os gêneros dessas pessoas estão estabelecidos quando optam por quaisquer mudanças (BENEVIDES, s/d).

De acordo com a minha pesquisa de campo existe uma fronteira que impõe limites em se falar de transexualidade, racismo e machismo. Existe o respeito, todavia, não é permitido tratar do assunto abertamente, me conduzindo a refletir sobre moral e valores da comunidade. A exemplo disso, percebe-se a intensão de encaixar pessoas LGBT aos padrões morais de lideranças (PLATERO, 2019: 4) e dos "fardados" que também reproduzem os argumentos heteronormativos e cisnormativos que prevalecem na sociedade (não dos ensinamentos do "plano espiritual"). Platero (2019) relata que quando as pessoas da igreja carioca onde ela é "fardada" conheceram sua sexualidade desviante, configurou-se a seguinte situação:

\author{
Tabu (de um lado) \\ Orientada pela moral da liderança
}

Instrução espiritual (de outro)

Orienta o autoconhecimento e não a correção

Embora as situações vividas por Platero dizem respeito à sexualidade, a moral que justifica a homofobia é a mesma que fundamenta a transfobia. De constrangimentos sutis a situações explícitas que as pessoas trans são submetidas quando tentam acesso à bebida sagrada nos centros "daimistas". Se tornou corriqueiro as experiências de adeptos que chamam essas pessoas no privado para uma série de interrogações: “afinal, o que você é?” ou "deixa eu ver sua identidade!".

Desde 2016 escuto alguns relatos a respeito da temática. Uma mulher trans que visitou uma igreja "daimista" de Marabá e é questionada de forma invasiva, em desrespeito à sua identidade de gênero. A mesma situação acontece com o interlocutor trans masculino a qual está em processo de iniciação "daimista" na mesma igreja que eu participo. Ele relata que antes de iniciar a hormonização foi obrigado a integrar o batalhão feminino e que, posteriormente, retorna a esta mesma igreja meses após o início da transição hormonal, mas desta vez é inserido no batalhão masculino sem constrangimentos explícitos. Seu relato afirma a problemática da "passabilidade de gênero".

[...] na primeira ida não foi uma experiência muito legal por conta da desinformação do centro sobre a questão da diversidade de gênero a qual eu sou integrado, a qual eu me sinto, né. Eu sou um homem trans e... quando eu fui participar desse trabalho eu tava era, em processo de transição, eu era "pré- T". No processo de transição hormonal nessa questão que eu ainda não tinha começado, ainda tinha características de estereótipos de características ditas femininas, né. E foi um pouco constrangedor, porque eu fui obrigado a ficar no sagrado a qual não representa a minha identidade de gênero, que foi o batalhão feminino, fui obrigado a ficar no batalhãofeminino, por conta que eu não tinha o documento retificado... eu não tinha meu nome retificado $e$ eu fui colocado... Não foi uma experiência legal porque eu não consegui me conectar com a corrente do trabalho.

E... a segunda vez que eu voltei lá, no mesmo centro depois de alguns meses sem ir eu 
fiquei no batalhão masculino, já tinha começado a minha transição hormonal e já tinha algumas mudanças visíveis, né, a olho nu. Questão da... do meu corpo, do meu rosto, minha voz. E eu fiquei no batalhão masculino e foi aí que eu consegui me incluir na corrente, foi a partir desse segundo trabalho. (JOÃO, 2021)

Anos se passam e Joãoํㅜㄹ que à época passava por conflitos pessoais, retorna ao Santo Daime, desta vez em uma outra igreja com objetivo de se reencontrar sob auxílio da bebida para o início do autoconhecimento da sua busca espiritual, segundo a cosmovisão "daimista".

\begin{abstract}
Eu defino essa bebida sagrada como um autoconhecimento de mim mesmo, sabe, do meu eu interior e... de uma grande importância para quem comunga ela, porque é uma bebida ancestral[...]. Ela é que me deu o fôlego de vida novamente porque antes de eu ter voltado a comungar o daime eu tava passando por muitos momentos dificeis, muitas lutas psicológicas. (JOÃO, 2021)
\end{abstract}

João decide se "fardar" após uma outra situação de constrangimento na qual o questionam se ele é homem ou mulher. Segundo ele, o que o mantém na religião é sua fé na bebida, a confiança nas instruções espirituais de Irineu, dos caboclos e da mãe terra. Para ele o que vale é o respeito, o amor e a humildade, virtudes da cosmologia "daimista". Para João, a "energia não tem gênero" e se firma nessa concepção para continuar no Santo Daime.

\begin{abstract}
Eu acho que a energia não tem gênero porque quando a gente comunga o daime em nenhum momento a gente recebe instrução de que a gente tá errado que aquele não é nosso lugar, que a gente não é homem porque a gente não tem um pênis, já começa por aí. A essência é porque é de dentro pra fora que a gente se sente quem a gente é, e como a gente se identifica com a matéria é aqui dentro primeiro. [...] E as energias não ditam, como que falei, que pra ser homem tu tem que ter um pênis e que tem que ter uma vagina pra ser mulher eu acho que se a energia tivesse gênero ela já ia os instruir e falar: não, vocês tem que ficar naquele lugar porque você é... você não é um homem porque você, é, não tem essa genital. Eu acho que se as energias tivessem gênero a gente já ia ser barrado a partir da própria espiritualidade, independente de se a gente comungasse o daime ou se a gente fizesse parte de outra doutrina espírita. (JOÃ̃, 2021)
\end{abstract}

Por isso escolhi o hino presente na epígrafe inicial deste artigo, já que além da comoção que ele produz durante os "trabalhos", também é um ensinamentos do "professor", isto é, do Mestre Irineu. Apesar disso, os constrangimentos não cessaram.

Nesta mesma igreja, durante uma entrevista semiestruturada que fiz com um dirigente na fase exploratória do trabalho de campo antropológico, pergunto qual a sua orientação sexual, ele se mostra bastante incomodado com a pergunta. Após o "trabalho", o dirigente me procura e retoma este tópico da entrevista. Ele demonstrou curiosidade sobre meu questionamento durante a entrevista. Expliquei para ele que a minha intensão era traçar o perfil social dos daimistas. Em sua resposta, afirmou que não é preconceituoso, pois respeita as "fardadas" lésbicas e "visitantes" homossexuais que frequentam aquele centro. Entretanto, sempre que um discurso como este é proferido, é comumente acompanhado de um "mas".

A conjunção utilizada por ele veio acompanhada de uma série de alegações de que não permitiria que uma pessoa "transformista" participasse do "trabalho" no "batalhão" que "não condiz com o sexo biológico" dela. Me senti paralisada por alguns minutos porque eu tinha receio de afetar a pesquisa ou interferir, de alguma forma, no trabalho de campo. As únicas palavras que consegui falar foi que o termo correto seria transgênero. Quando cheguei em casa, comentei sobre o ocorrido com meu companheiro, um dos interlocutores trans da pesquisa. 
Meses após a entrevista com este dirigente, aconteceu um "feitio" a qual fui convidada a participar. Durante ritual de feitura do chá existe uma divisão de trabalho de acordo com os gêneros (feminino e masculino). As muheres trabalham na colheita e lavagem de folhas da chacrona, enquanto os homens ficam responsáveis pelo trabalho com o cipó jagube e cozimento do "daime". Este trabalho de campo foi crucial para a decisão da abordagem de gênero na minha pesquisa, sobretudo, porque naquela oportunidade o líder responsável pelo convite me relata uma experiência na "força", na qual ele aprende sobre as questões de gênero olhando profundamente para dentro de si. Na sua visão, é preciso encontrar o "equilíbrio energético" do "sagrado feminino e masculino".

Os "trabalhos de feitio" também se mostraram importantes para a pesquisa. João relata a sensação de ser obrigado a performar um modelo de masculinidade ou virilidade.

E teve um episódio também que ocorreu que é, esse engajamento que esse mesmo irmão de querer impregnar a agressividade da heteronormatividade compulsória no ato de pegar a panela do feitio pra despejar o resto do cipó e da rainha que tem que ser colocado... que tem que ser respeitado do início ao fim e eu fui colocar na panela e eu peguei um pano pra me proteger do calor já que tava quente e a panela fica no fogo por horas, e eu peguei um pano pra despejar os restos das folhas e do cipó quando eu me abaixei pra colocar a panela do modo certo pra sair todos os ingredientes que tinha dentro, né, do cipó e da folha e quando eu levantei, que o vapor já tinha dado uma amenizada, mas ainda tava quente e eu fui me proteger novamente com um pano, foi quando um deles pegou a panela sem nada e falou que é assim que homem pega numa panela. (JOÃO, 2021)

O relato acima demonstra que a virilidade é percebida no processo de limpeza das panelas. Ademais, observei que, provavelmente, quanto mais rápido e por mais tempo a pessoa macera o cipó Jagube, mais "homem" o é. Ou quanto mais peso e temperatura da panela a pessoa consegue sustentar com ou sem uso de um tecido de apoio. É possível que a virilidade esperada dos homens também apareça na comunhão da bebida, pois poucos homens pegam as frutas que estão sempre postas à mesa para amenizar o incomodo com o sabor forte do "daime" (do lado esquerdo - lado das mulheres).

O gênero é uma construção sociocultural do ocidente afirma Oyèrónkẹ Oyěwùmí (2004). A autora constrói seu argumento acerca dos conceitos de gênero como uma crítica aos fundamentos eurocêntricos de família e mulher. A principal consequência disso, segundo Oyěwùmí (2004) é a expansão da Europa e o estabelecimento da hegemonia cultural europeia e americana em todo o mundo. A noção de virilidade/masculinidade está fundamentada nas concepções ocidentais, que transforma uma ideia em norma.

A partir da leitura desse texto e de outras referências bibliográficas de pesquisadoras e ativistas feminismo negro e do Mulherismo Afrikana, como: Djamila Ribeiro (2015), Grada Kilomba (2019), Aza Njeri e Katiúscia Ribeiro (2019), questiono se é possível observar a aproximação da cultura "daimista" com as concepções ocidentais? As observações e interpretações elencadas no texto, bem como as problematizações em diálogo com perspectivas descoloniais, são reflexões em curso, pois acredito que possam me ajudar a pensar a figura do Mestre fundador da doutrina para além de afirmações generalistas.

\section{Reflexões em curso}

Não pretendo esgotar no texto as reflexões e questionamento e também não tenho a intenção de resolver nenhuma problemática percebida em campo. 
Em síntese, pretendi com este trabalho, descrever algumas situações que sustentam a minha pesquisa. Realizo um breve diálogo com outras pesquisadoras ayahuasqueiras, as quais se esforçam para pensar o Santo Daime, seus valores, suas morais e seus contextos históricos.

Procurei contestar o meu lugar de fala enquanto pesquisadora ayahuasqueira, e cis, quando faço a inter-relação de questões éticas e metodológicas do campo dos psicoativos com abordagem nas experiências de pessoas trans visitantes, fardadas ou fardantes na "doutrina da floresta". Os atores envolvidos no trabalho demonstram interesse em continuar frequentando os trabalhos da igreja, de exercer suas espiritualidades. Eles se mostram assíduos na sua fé e demonstram que não pretendem desistir da caminhada do autoconhecimento.

As temáticas, como as elencadas neste trabalho merecem atenção e devem pensadas no âmbito científico como a possibilidade de novos diálogos com pesquisadoras ayahuasqueiras (ou não) para continuar problematizando o gênero, seja como uma construção social ou formas de organização social. Em concordância com as pessoas transgêneros, transexuais, travestis, não binários, andrógenas e cisgêneros que acompanho nas redes sociais e no dia a dia, é relevante encerrar este texto afirmando que as pessoas podem, devem e tem o direito de viver e se expressar sem medo de retaliações.

Recebido em 30 de janeiro de 2021.

Aprovado em 21 de junho de 2021.

\section{Referências}

BENEDITO, Camila. Um convite para a diversidade nos grupos ayahuasqueiros. Chacruna Latinoamérica, 2020. Disponível em: https://chacrunala.org/um-convite-para-a-diversidade-nos-grupos-ayahuasqueiros/. Acesso: 25 de janeiro de 2021.

BENEVIDES, Bruna. Como acessar o SUS para questões de transição. S/D. Disponível em: https://antrabrasil.org/2020/o7/27/como-acessar-o-sus-paraquestoes-de-transicao/. Acesso: 15/03/2021.

CLIFFORD, James; MARCUS, G. (orgs.). A escrita da cultura: poética e política da etnografia. Tradução: Maria Coelho. Rio de Janeiro: Papéis Selvagens, 2016.

FAVRET-SAADA, J. Ser afetado. Cadernos de campo, 13: 155-161, 2005.

INGOLD, Tim. Antropologia pra que serve? Petrópolis: Editora Vozes, 2019. 
KILOMBA, Grada. Memórias da plantação: episódios de racismo cotidiano. Rio de Janeiro: Editora Cobogó, 2019.

MAAS, Matheus. Quando o "nativo" é pesquisador - Notas sobre o trabalho de campo no Santo Daime. Ponto Urbe, 17, 2015.

MAECRAE, E. Guiado pela lua: xamanismo e uso ritual da ayahuasca no culto do Santo Daime. São Paulo: Brasiliense, 1992.

MOIRA, Amara. Vidas Trans: a coragem de existir. Bauru, SP: Astral Cultural, 2017.

NJERI, Aza; RIBEIRO, Katiúscia. Mulherismo Africano: práticas na diáspora brasileira. Currículo sem Fronteiras, 19 (1): 595-608, 2019.

OYĚWÙMÍ, Oyèrónkẹ. Conceituando o gênero: os fundamentos eurocêntricos dos conceitos feministas e o desafio das epistemologias africanas. CODESRRIA Gender Series. Tradução: Juliana Araújo Lopes. Volume 1, Dakar, 2002;

PLATERO, Lígia. Uma experiência de casamento no Santo Daime. Blog Bia Labate, 2017. Disponível em: https://www.bialabate.net/news/uma-experienciade-casamento-homossexual-no-santo-daime. Acesso: 20 de dezembro de 2020.

RIBEIRO, Djamila. O que é lugar de fala? Belo Horizonte: Letramento, 2017.

SONZA, Quesia. FUI EXPULSA DO CANDOMBLÉ POR SER TRANS! Paraíba, nov., 2020. Instagram: @quesiasonzaa. Disponível em: https://www.instagram.com/tv/CBA1oRVAig6/

VELHO, Gilberto. "Observando o Familiar". In: Individualismo e cultura. Rio de Janeiro: Zahar, 2004.

WHYTE, William Foote. Sociedade de esquina. Rio de Janeiro: Jorge Zahar Editor, [1943] 2005. 